Part of Journal of Research of the National Bureau of Standards, Volume 14, February 1935

\title{
SPECIFIC VOLUME, COMPRESSIBILITY, AND VOLUME THERMAL EXPANSIVITY OF RUBBER-SULPHUR COM- POUNDS
}

\author{
By Arnold H. Scott
}

\section{ABSTRACT}

The specific volume, compressibility, and volume thermal expansivity of rubber-sulphur specimens containing from 3 to 31 percent of sulphur have been determined at temperatures from 10 to $85^{\circ} \mathrm{C}$ for pressures up to 800 bars (790 atmospheres). The specific volume was determined at atmospheric pressure by means of a pycnometer. The specific volumes at the other pressures were obtained from measurements of the lengths of rods of the materials as the pressures were applied. The compressibilities and volume thermal expansivities were computed from these results. The effect of pressure on the specific volume was found to be a function of the sulphur content and the temperature. The specific volume may be computed from the equation $V=V_{a}\left(1+\alpha P+\beta P^{2}\right)$, where $V_{a}$ is the specific volume at atmospheric pressure, $P$ is the pressure, and $\alpha$ and $\beta$ are coefficients. For temperatures between 10 and $85^{\circ} \mathrm{C}$ and for specimens containing up to $X$ percent of sulphur where $X$ is given by the equation $X=(T+30) / 3.7$ and $T$ is the temperature in degrees centigrade, $V_{a}, \alpha$ and $\beta$ have the following values:

$$
\begin{aligned}
V_{a} & =1.1015+0.00073(T-25)-X[0.00932+0.000007(T-25)] \\
\alpha & =-10^{-6}\{53.7+0.258(T-25)-X[1.35-0.00217(T-25)]\} \\
\beta & =10^{-0}[12.0+0.083(T-25)-0.34 X]
\end{aligned}
$$

For temperatures between 10 and $85^{\circ} \mathrm{C}$ and for specimens containing between $X$ and 32 percent of sulphur where $X$ is given by the equation $X=(T+42) / 3.7$, $V_{a}, \alpha$, and $\beta$ have the following values:

$$
\begin{aligned}
V_{a} & =1.0450+0.00038(T-25)-X[0.00601+0.0000064(T-25)] \\
\alpha & =-10^{-6}\{35.6+0.326(T-25)-X[0.352+0.00672(T-25)]\} \\
\beta & =10^{-9 !}[9.1+0.0683(T-25)-0.221 X]
\end{aligned}
$$

The volume thermal expansivity for the specimen containing 3 percent of sulphur decreased from $6.7 \times 10^{-4}$ at 1 bar to $5.0 \times 10^{-4}$ at 800 bars, while for the specimen containing 31 percent of sulphur, it decreased from $2.2 \times 10^{-4}$ to $1.7 \times 10^{-4}$. The compressibility varied from a maximum of $66 \times 10^{-6}$ to a minimum of $21 \times 10^{-6}$.

\section{CONTENTS}

I. Introduction _...

II. Method of determining specific volume

III. Description of apparatus.

IV. Preparation of specimens

V. Results_._. 107

1. Specific volumes at atmospheric pressure

2. Specific volumes at high pressures _._.

3. Volume thermal expansivity

4. Compressibility

VI. Discussion 


\section{INTRODUCTION}

The specific volume, compressibility, and volume thermal expansivity of rubber-sulphur compounds ${ }^{1}$ containing from 3 to 31 percent of sulphur have been measured at pressures from 1 to 800 bars and at temperatures from 10 to $85^{\circ} \mathrm{C}$. The results are expressed in tables, curves, and equations so that, within the indicated limits, the value of any of the above properties can be readily determined for a compound of specified composition under specified conditions of temperature and pressure.

Specific volume, which is the reciprocal of the density, has been used throughout this paper because this term is the one which is used directly in the definitions of compressibility and volume thermal expansivity. The work of Kimura and Namikawa ${ }^{2}$ indicated that the specific volume of rubber-sulphur compounds at atmospheric pressure was a linear function of the temperature. The use of the specific volume thus leads to equations which are simpler than if the density is used.

\section{METHOD OF DETERMINING SPECIFIC VOLUME}

The specific volume of a material at atmospheric pressure was determined by means of a pycnometer. The specific volumes at other pressures were obtained from measurements of the changes in length of a rod of the same material when subjected to different pressures.

The procedure used in the determination of the change in length was to make measurements at successive pressures through a pressure cycle at a fixed temperature. The pressure was increased in steps of 200 bars $^{3}$ up to 800 bars, allowing time for temperature equilibrium in each case. The same measurements were then made as the pressure was decreased by steps of 200 bars back to atmospheric pressure. A group of measurements obtained when carrying the specimen through this pressure cycle is called a set of data. A repetition of this at the same or another temperature is considered another set.

The specific volume at a given pressure was computed from the change in length of the rod when the pressure was applied. Assuming the material of the rod to be isotropic, then the volume change with pressure is proportional to the cube of the length. ${ }^{4}$ Let

$L_{a}=$ the length of the rod at atmospheric pressure (approximately 1 bar)

$\Delta L=$ the change in length of the rod when the pressure has been been increased to any pressure, say $P$ bars

$V_{a}=$ the specific volume at atmospheric pressure (approximately 1 bar)

$V=$ the specific volume at $P$ bars

1 This paper is one of a series dealing with the properties of rubber-sulphur compounds. See BS Tech. Pap. 19, 669 (1925) T299; BS Sci. Pap. 22, 383 (1927) S560; and BS J. Research 11, 173 (1933) RP585. A need for information regarding the compressibility of rubber arose in connection with the determination of the effect of pressure on the electrical properties of rubber where a knowledge of the change in dimensions was required.

2 J. Soc. Chem. Ind., Japan, 32 (supplemental binding) 196 B (1929).

3 The bar is defined as $10^{6}$ dynes/cm² and is equal to 0.987 normal atmosphere.

1 The assumption that the samples were isotropic was based on the method of preparation and is confirmed by recent photoelastic studies on vulcanized rubber by Thibodeau and McPherson, J. Research NBS 13, 887 (1934) RP751. 
Then

or

$$
\frac{V}{V_{a}}=\frac{\left(L_{a}-\Delta L\right)^{3}}{L_{\mathrm{a}}^{3}}
$$

$$
V=V_{a}\left[1-3 \Delta L / L_{a}+3\left(\Delta L / L_{a}\right)^{2}-\left(\Delta L / L_{a}\right)^{3}\right]
$$

The last term was found to be negligible for pressures used in this investigation.

The specific volume was found to vary with the pressure in a manner described by the equation:

$$
V=V_{o}\left(1+\alpha P+\beta P^{2}\right)
$$

where $P$ is the pressure in bars, $V_{o}$ is the specific volume at zero pressure, and $\alpha$ and $\beta$ are characteristic coefficients which depend on the temperature and the composition of the rubber-sulphur compounds. ${ }^{5} \quad V_{o}$ is equal to $V_{a}$ within experimental error and therefore $V_{a}$ is used in the above equation in place of $V_{o}$. The approximate values of the coefficients may be obtained from measurements of change in length by selecting two observations from a set, preferably the change in length at maximum pressure and the change in length at about one-half maximum pressure. Let

$V_{1}=$ specific volume at $P_{1}$ bars

$V_{2}=$ specific volume at $P_{2}$ bars (about 2 times $P_{1}$ )

$\Delta L_{1}=$ change in length from 1 to $P_{1}$ bars

$\Delta L_{2}=$ change in length from 1 to $P_{2}$ bars

Then from eq 2

$$
\begin{aligned}
& V_{1}=V_{a}\left(1+\alpha P_{1}+\beta P_{1}^{2}\right) \\
& V_{2}=V_{a}\left(1+\alpha P_{2}+\beta P_{2}^{2}\right)
\end{aligned}
$$

and from eq 1 , neglecting the cubic term

$$
\begin{aligned}
& V_{1}=V_{a}\left[1-3 \Delta L_{1} / L_{a}+3\left(\Delta L_{1} / L_{a}\right)^{2}\right] \\
& V_{2}=V_{a}\left[1-3 \Delta L_{2} / L_{a}+3\left(\Delta L_{2} / L_{a}\right)^{2}\right]
\end{aligned}
$$

Solving these equations we find

$$
\begin{aligned}
& \alpha=\frac{3}{P_{2}-P_{1}}\left\{\frac{P_{1}}{P_{2}}\left[\frac{\Delta L_{2}}{L_{a}}-\left(\frac{\Delta L_{2}}{L_{a}}\right)^{2}\right]-\frac{P_{2}}{P_{1}}\left[\frac{\Delta L_{1}}{L_{a}}-\left(\frac{\Delta L_{1}}{L_{a}}\right)^{2}\right]\right\} \\
& \beta=-\frac{3}{P_{2}-P_{1}}\left\{\frac{1}{P_{2}}\left[\frac{\Delta L_{2}}{L_{a}}-\left(\frac{\Delta L_{2}}{L_{a}}\right)^{2}\right]-\frac{1}{P_{1}}\left[\frac{\Delta L_{1}}{L_{a}}-\left(\frac{\Delta L_{1}}{L_{a}}\right)^{2}\right]\right\}
\end{aligned}
$$

The values of $\alpha$ and $\beta$ obtained from these equations for a given specimen were used in eq 2 and the resulting equation was then checked against all the values of the specific volume of this specimen,

${ }^{5}$ The cubic term in the equation which Adams and Gibson found to describe the change in volume of rubber with pressure (see J. Wash. Acad. Sci. 20, 213 (1930)) was unnecessary over the short pressure range used in the present investigation. 
determined from its change in length. A slight revision in the values of the coefficients was necessary in a few cases in order to make the equation more closely represent the complete data of a set.

Compressibility, $\sigma$, is defined as the decrease in volume per unit volume for a unit increase in pressure at constant temperature. That is

$$
\sigma=-\frac{1}{V_{0}} \frac{d V}{d P}
$$

Thus by differentiating eq 2 we obtain

$$
\sigma=-\alpha-2 \beta P
$$

The compressibility may be determined by simply giving $\alpha$ and $\beta$ the values computed from the equations above.

The volume thermal expansivity is defined as the increase in volume per unit volume for an increase of $1^{\circ}$ of temperature at constant pressure. Since the volume thermal expansivity was determined only for those temperature ranges in which the specific volume was a linear function of the temperature, the expansivity was computed from the slope of the line obtained by plotting the specific volume against the temperature.

\section{DESCRIPTION OF APPARATUS}

The specific volume measurements at atmospheric pressure were made with the pycnometer described by Ashton, Houston, and Saylor. ${ }^{6}$ A sketch of this pycnometer is shown in figure 1 . The pycnometer was made of glass and had a capacity of about $25 \mathrm{~cm}^{3}$.

The specific volume was determined from the weight of the specimen and the weight of the pycnometer containing first the confining liquid and then the confining liquid and specimen. Water was used as the confining liquid. Investigation showed that the absorption of water by the rubber-sulphur compounds had a negligible effect on the results. The height of the confining liquid in the capillary tube was adjusted after the pycnometer and contents had been kept in a constant temperature bath for 30 minutes to insure uniform temperature. The bath was controlled to $0.1^{\circ} \mathrm{C}$ and weighings were made to $1 \mathrm{mg}$. After adjustment at the desired temperature the pycnometer and its contents were brought to a temperature near that of the room before it was weighed. This was done by placing it in a water bath at room temperature for a few minutes.

No grease was used on the ground-glass joints of the pycnometer and therefore slow evaporation of the water took place, making the weight a function of the time which elapsed after the liquid was adjusted in the capillary tube. However, a strict time schedule was employed so that measurements could be repeated to $5 \mathrm{mg}$ or less, which resulted in an error of less than 0.1 percent in the determination of specific volume.

The specific volume, in most cases, was also determined at $25^{\circ} \mathrm{C}$ on the entire specimen used in the pressure measurements. This was determined by weighing the specimen in air and in water.

6 BS J. Research 11, 243 (1933) RP587. This pycnometer is a modification of the one used by Richards, Hall, and Mair. J. Am. Chem. Soc, 50, 3308 (1928). 
The change in length of a specimen with pressure was determined with the apparatus shown diagrammatically in figure 2 . The specimen, which was inclosed in the pressure chamber, was suspended at its upper end. The glass scale which was fastened to the lower end extended between the two glass pressure windows. The scale was illuminated through one window and viewed by means of a microscope through another window.

The pressure chamber consisted of a steel pipe known commercially as "double extra heavy", having a heavy fitting on each end. The upper fitting had two openings, one of which allowed the insertion of the specimen and the other the connection to the pressure pump. The lower fitting had two openings which were opposite each other and into which the steel plugs carrying the pressure windows were screwed. The fittings were equipped with lead rings which could be firmly pressed into the threads by means of set screws, thus producing tight joints.

The pressure chamber was hung from a bracket on a brick wall. This bracket had a flat horizontal iron shelf about $9 \mathrm{~mm}$ thick from which was cut a $U$-shaped section of such size that the plug in the upper end of the pressure chamber would just fit into it. Thus the weight of the chamber was supported by the shoulder of the plug resting on the shelf. The microscope used to view the scale was mounted on another bracket which was also fastened to the brick wall. Since a set of measurements was made at constant temperature, the distance between the brackets was assumed to remain fixed during this set of observations. Any changes in dimensions of the pressure chamber due to pressure changes had no effect on the measurement of the length of the rubber rod. A prism which was mounted on the bracket with the microscope and which is not shown in the figure was used so that the microscope could be mounted at right angles to the line through the pressure windows. This allowed the operator to make observations while facing the wall and kept the face of the observer out of danger in case the pressure window failed. The lower end of the pressure chamber was held against two guides by spring clips not shown in the figure.

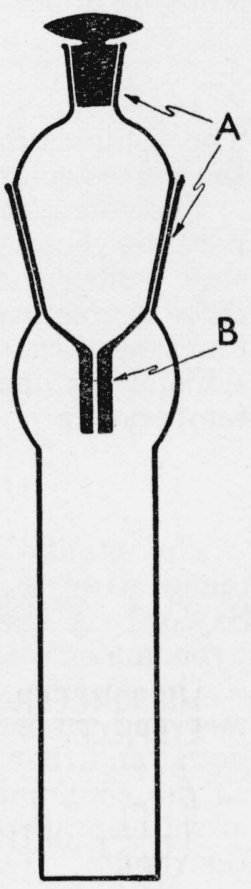

Figure 1.-Apparatus for specific volume determinations at atmospheric pressure.

A, ground glass joints; $B$, volume adjustment mark.

The rods of soft rubber were fastened to the plug at the upper end by cementing them with a commercial thermoprene cement. The rods of hard rubber were screwed to the plug. A machine screw about $6 \mathrm{~mm}$ long was fastened to the end of the plug. A hole was drilled and tapped in the end of the rod and this was then screwed onto the machine screw. Some of the semihard rubbers were both screwed and cemented to the plug.

An aluminum rod $17 \mathrm{~cm}$ long was fastened to the lower end of the rubber rod by the same method used to fasten the rod to the plug. 
This metal rod was necessary because the density of some of the soft rubbers was less than that of water and a weight was needed to counteract the tendency of the rod to float. An aluminum rod having a weight sufficient to supplement the weight of the least dense specimen was used on all specimens. The excess weight of the metal rod for the more dense specimens did not affect the measurements appreciably since this excess weight was small and the stiffness of the rubber specimens increased with the density.

The engraved glass scale, which was $3 \mathrm{~cm}$ long, was fastened to the lower end of the aluminum rod by means of a frame and clip. The

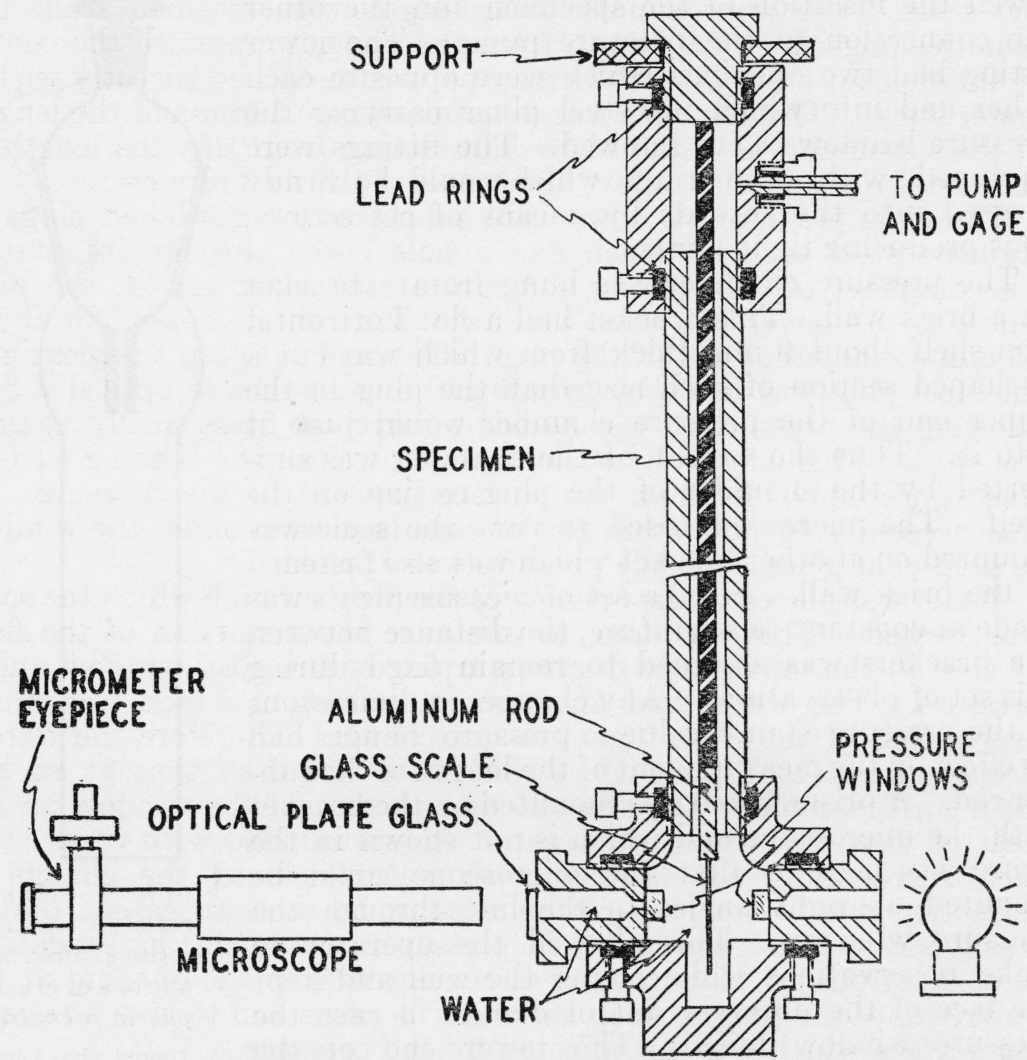

FigURE 2.-Apparatus used in the determination of the change in length of a cylindrical specimen with pressure.

clip kept the end of the scale pressed firmly against the end of the rod. The changes in position of the scale were due to changes in length of both the rubber and aluminum rods. The small corrections for the change in length of the aluminum rod were computed from the values of compressibility given in the International Critical Tables. ${ }^{7}$

The scale was ruled with a diamond point on the platinized surface of a piece of optical plate glass. Since the scale was illuminated from behind, the lines appeared bright on a dark field. The lines

\footnotetext{
7 International Critical Tables 3, 46.
} 
were ruled on a precision dividing engine at $0.5 \mathrm{~mm}$ intervals and were designated by engraved numbers. This scale was used to calibrate the micrometer eyepiece of the microscope. One millimeter was equivalent to 346 divisions on the micrometer eyepiece.

The motion of the scale and hence the change in length of the specimen was measured by means of the micrometer eyepiece of the microscope. Three lines of the scale were visible in the field of the microscope. The crosshair was set on the line nearest the center of the field and the change in length of the rod was determined from the reading of the micrometer eyepiece and the number of the line on the scale. The approximate total length was obtained from the same readings since the length from the upper support to the center of the field of view of the microscope was measured directly with a meter stick. This distance was determined to $0.5 \mathrm{~mm}$ and the length of the specimen was obtained by subtracting from this the length of the metal rod and scale above the center of the field of view.

The glass pressure windows were supported by hardened plugs of stainless steel each of which had a hole bored through its center. The diameter of this hole was $6 \mathrm{~mm}$ at the inner end of the plug where it was covered by the window. This was increased to about $15 \mathrm{~mm}$ at the other end of the plug. The seal between the glass and the steel plug was made by grinding the two surfaces optically flat, allowing the pressure of the liquid to force the glass firmly against the steel. This effectively sealed the joint since the bearing surface was appreciably less than the surface exposed to the pressure. It was necessary to put a thin film of canada balsam under the window to hold it in place until the pressure was applied.

Water was placed in the opening of the plug through which the scale was viewed. This was done to minimize the distortion of the field of view in the microscope due to warping of the glass window under pressure. The water had an index of refraction which was much nearer that of the glass than was that of air. Therefore the refraction at the water-glass surface was much less than that at an airglass surface, making the effect of the warping of the window on the field of view less when the window was surrounded with water. In fact, surrounding the window with water reduced the change in refraction due to warping of the window to such an extent that it was found to be negligible for the pressures used in this investigation. A piece of optical plate glass was cemented over the opening at the outer end of the plug to keep the water in place and to give a refracting surface which was not affected by the pressure.

The pressure chamber was mounted in a constant temperature air bath provided with numerous baffles and valves so that the air flow could be readily changed and the same temperature could be maintained throughout the pressure chamber. The temperature of the chamber was measured by 3 thermocouples soldered to it, one near the top, one near the middle, and one at the bottom. It was possible, with close watching, to keep the temperature of the chamber as indicated by the 3 thermocouples within $0.1^{\circ} \mathrm{C}$ of the desired temperature.

The pressure was measured by a resistance gage of the type described by Gibson. ${ }^{8}$ A diagram of this gage is shown in figure 3 . The manganin resistance coil was placed in a steel chamber which

\footnotetext{
8 J. Am. Chem. Soc. 56, 4 (1934).
} 
was connected to the pressure chamber by small-bore steel tubing. The leads to the coil were made of piano wire and were brought out through a packing of limestone, rubber, and talc. The limestone and talc were machined to a tight fit. The rubber was made oversize and had to be squeezed into place. The whole packing was forced into place with a pressure of several thousand pounds. To do this a piece of steel was made to hold the plug and a plunger was made to place over the packing. This was then placed in a press and the packing forced into place. The packing was kept in place by the friction against the sidewalls. Pressure applied to the gage chamber

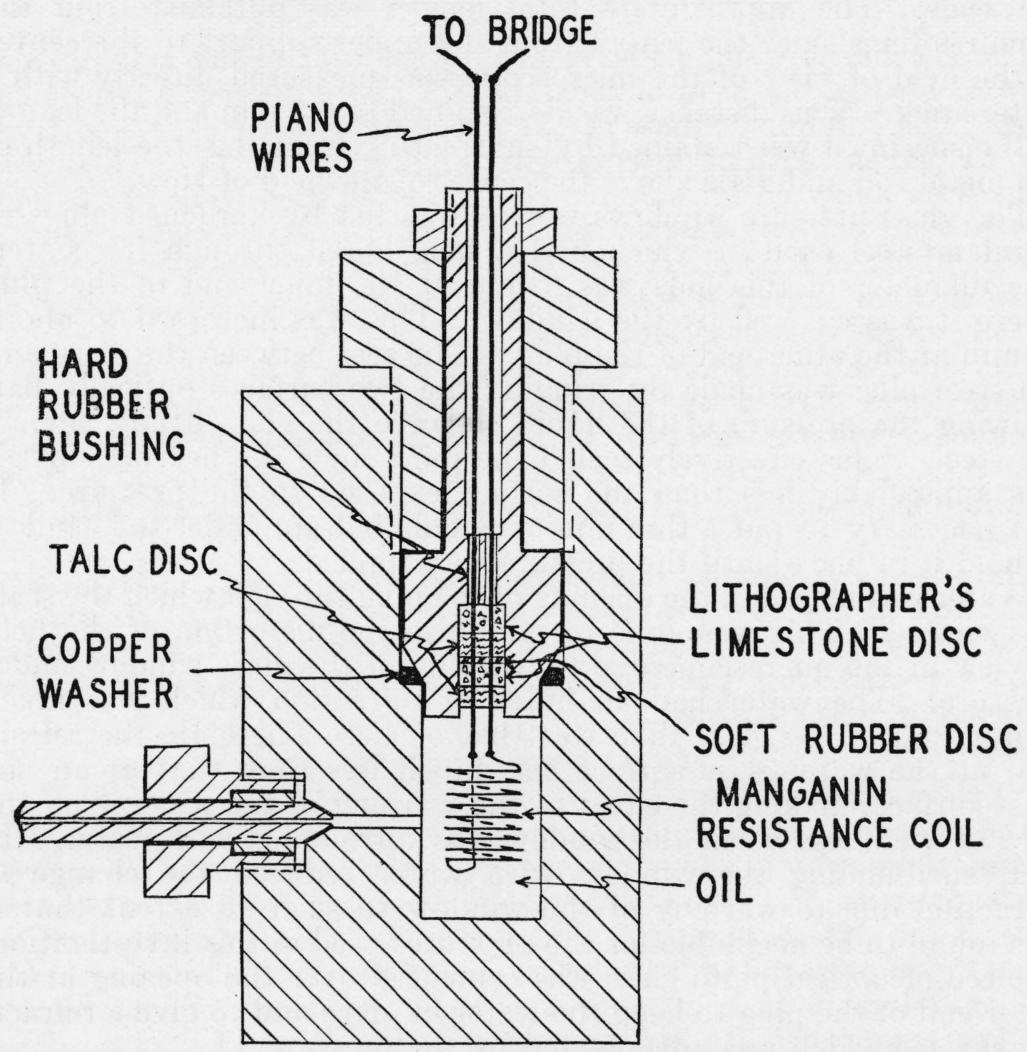

FIGURE 3.-Resistance pressure gage.

forced the packing closer into the plug opening and more effectively sealed it. There was no tendency for the lead wires to creep with this method of packing.

The coil was made of no. 38 manganin wire and had a resistance of about $101 \mathrm{ohms}$. It was wound in a single layer on a light cylinder of very thin paper. The form was preserved by covering the coil with a thin coat of shellac and baking it in an oven for several hours. The coil was seasoned under a pressure of 8,000 bars. A light insulating oil was used as the pressure medium surrounding the coil. Since water was used in the rest of the pressure apparatus it was necèssary to put a $U$-tube filled with mercury in the pressure line leading to the gage. 
The resistance of the coil was measured with a Wheatstone bridge capable of measuring resistance to $0.0001 \mathrm{ohm}$. The gage and bridge were placed in a carefully controlled temperature bath of oil. A change in pressure of 1 bar changed the resistance of the coil about $0.0002 \mathrm{ohm}$ so that a change in pressure of $1 / 2$ bar could be readily measured. Twenty to thirty minutes were allowed after the pressure had been applied for conditions to reach equilibrium before measurements were made, since a change in pressure affected the temperature equilibrium.

\section{PREPARATION OF SPECIMENS}

The specimens were made from purified rubber and sulphur and were molded in the form of rods about $1 \mathrm{~cm}$ in diameter and $85 \mathrm{~cm}$ long. The sulphur content of the different specimens ranged from 3 to 31 percent with no interval greater than 6 percent. The specimens were analyzed for sulphur content after they were vulcanized. The sulphur content was determined by burning a weighed sample of the rubber in a bomb with oxygen, absorbing the products of combustion in an alkaline solution, and determining the sulphur as barium sulphate as described by Mease. ${ }^{9}$

The purification of the rubber and the mixing of the rubber and sulphur were carried out as described in a former paper. ${ }^{10}$ The specimens were vulcanized in a mold in steam at $148^{\circ} \mathrm{C}$ for about 20 hours. This relatively long time of vulcanizing was for the purpose of bringing practically all the sulphur into combination with the rubber.

The specimens were carefully examined for porosity. The density of the rod as a whole was determined by weighing it in air and in water. Any rod which had a density appreciably less than the value to be expected from previous experience with specimens of similar composition was discarded.

\section{RESULTS}

The determinations of the specific volume are divided into two groups, those which were obtained with the pycnometer at atmospheric pressure and those which were obtained from the measurement of the change of length with pressure. The determinations at atmospheric pressure with the pycnometer were much more accurate and reproducible than those made under pressure. These results and the compressibility are presented in the form of curves. The values of the volume thermal expansivity are given in a table.

\section{SPECIFIC VOLUMES AT ATMOSPHERIC PRESSURE}

The values of the specific volumes at atmospheric pressure for various percentages of sulphur are shown in figure 4 where they are plotted against the temperature. The specific volume of the specimen containing 6 percent of sulphur was measured directly at $25^{\circ} \mathrm{C}$ only. The values at the other temperatures, as indicated by open circles, were obtained by interpolation when the specific volumes were plotted against the percentage of sulphur for each temperature.

? J. Research NBS 13, 617 (1934) RP731.

10 Scott, McPherson, and Curtis. BS J. Research 11, 173 (1933) RP585. 
The relation between the specific volume and temperature is linear for specimens containing up to 16.5 percent of sulphur. The relationship for specimens containing higher percentages of sulphur is

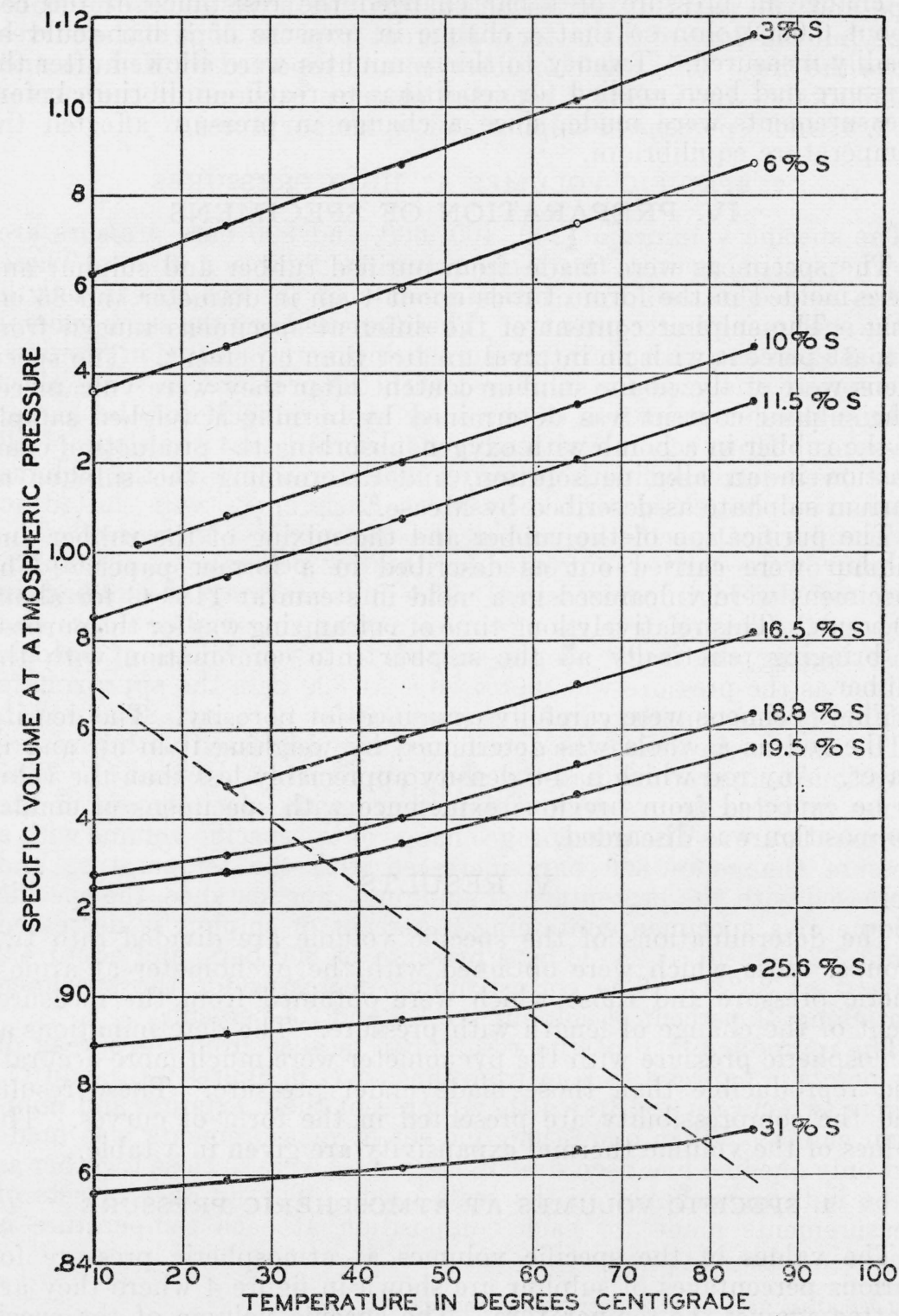

FIGURE 4.-Effect of temperature on the specific volume of rubber-sulphur compounds at atmospheric pressure.

The values represented by open circles were obtained by interpolation when the specific volumes were plotted against the percentage of combined sulphur.

such that the curve is linear in two sections but the slopes of the two sections differ. The slope for the higher temperatures is about that for the specimens containing 16.5 percent of sulphur or less 
Thus it is seen that if a line is drawn from approximately 0.97 at $10^{\circ} \mathrm{C}$ to approximately 0.86 at $85^{\circ} \mathrm{C}$, as shown in the figure, the curves or parts of curves above this line all have about the same slope and the parts of curves below this line have about the same slope, but the slope of the latter is different from the slope of the curves above the line. This was also observed and reported by Kimura and Namikawa. ${ }^{11}$ Bekkedahl ${ }^{12}$ reported changes in slope of the curves for 2,4 , and 6 percent of sulphur at low tempepatures.

\section{SPECIFIC VOLUMES AT HIGH PRESSURES}

The specific volumes at $200,400,600$, and 800 bars pressure are shown plotted against the temperature in figures 5 to 8 . These values were obtained from measurements of the changes in length of the specimens under pressure. These curves have the same general form as those at atmospheric pressure, being merely shifted in position. The spread of the points increased with the pressure, in some cases making the determination of the slope more difficult for the higher pressures. However, it was readily determined that the slope of all the curves decreased with pressure, which means that the volume expansivity decreased with pressure. Each curve was shifted to lower values of specific volume as the pressure was increased. The amount of the shift was greater for the low percentages of sulphur than for the high percentages. The line marking the boundarv between the curves or parts of curves having the smaller slopes and those having the larger slopes shifted to lower values of specific volume as the pressure was increased. At 800 bars the approximate position of this boundary line was from 0.94 at $10^{\circ} \mathrm{C}$ to 0.84 at $85^{\circ} \mathrm{C}$.

The manner in which the specific volume decreased with pressure at various temperatures is better shown in figures 9,10 , and 11 . The curves in these figures were obtained from the data shown in the previous figure. The percentage change of the specific volume with a pressure change of 800 bars increased with the temperature and decreased with the percentage of sulphur. For instance, the specific volume of a specimen containing 3 percent of sulphur is decreased about 3.3 percent at $25^{\circ} \mathrm{C}$ by a pressure of 800 bars, and about 4.2 percent at $85^{\circ} \mathrm{C}$. The corresponding decreases for the specimen containing 31 percent of sulphur are 1.8 and 2.4 percent.

The reproducibility of the results can be seen from the spread of the points in figures 4 to 8 , or from the curves in figures 9,10 , and 11 . Where two curves are drawn they represent the maximum and minimum values. When more than one set of measurements was made and only one line has been drawn, the values were so close together as to be indistinguishable on the scale used. The number of sets of measurements made for each composition at each temperature is shown in table 1.

11 J. Soc. Chem. Ind., Japan, 32 (supplemental binding), 196B (1929)

12 J. Research NBS 13, 411 (1934) RP717. 


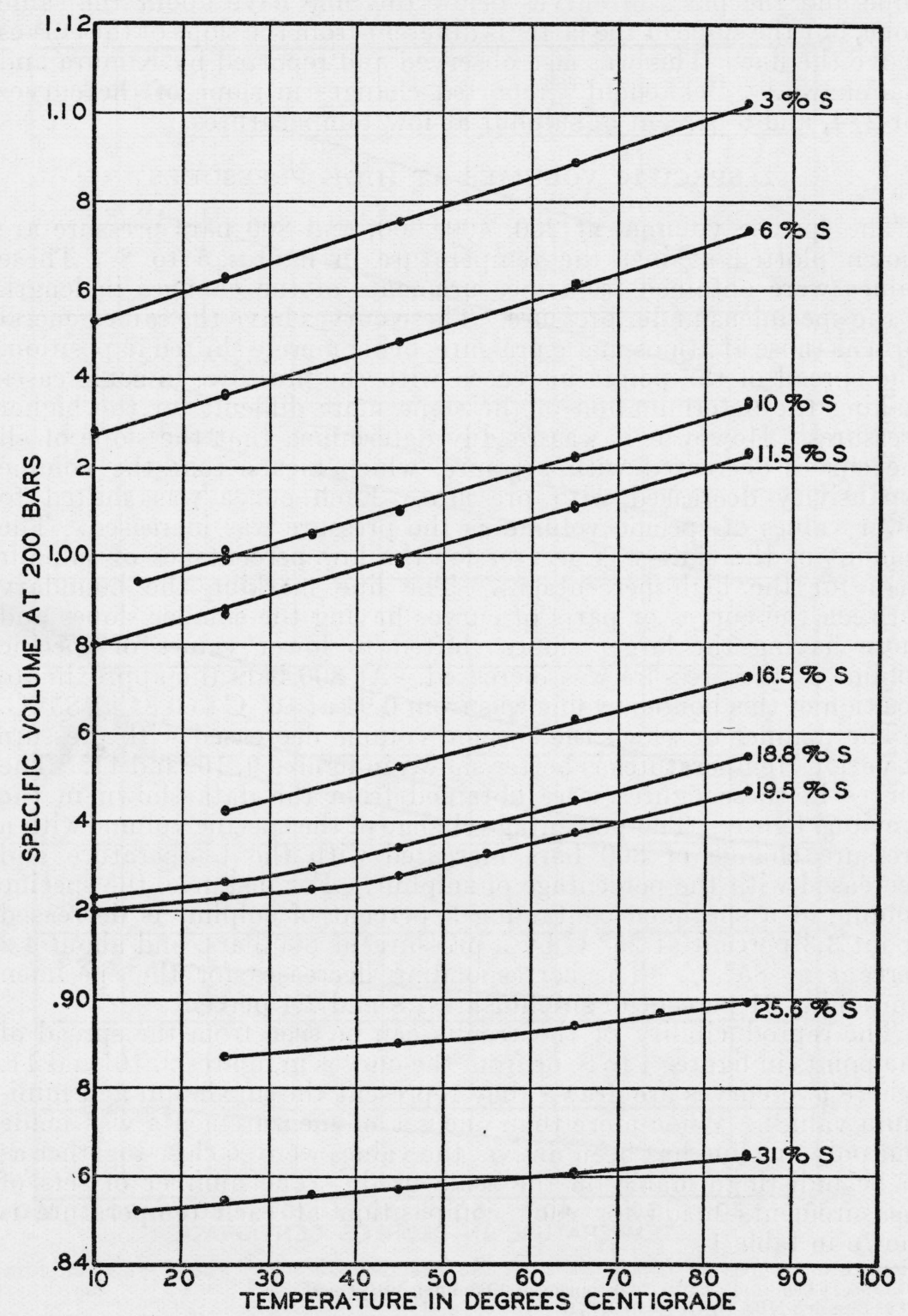

FIGURE 5.-Effect of temperature on the specific volume of rubber-sulphur compounds at 200 bars pressure. 


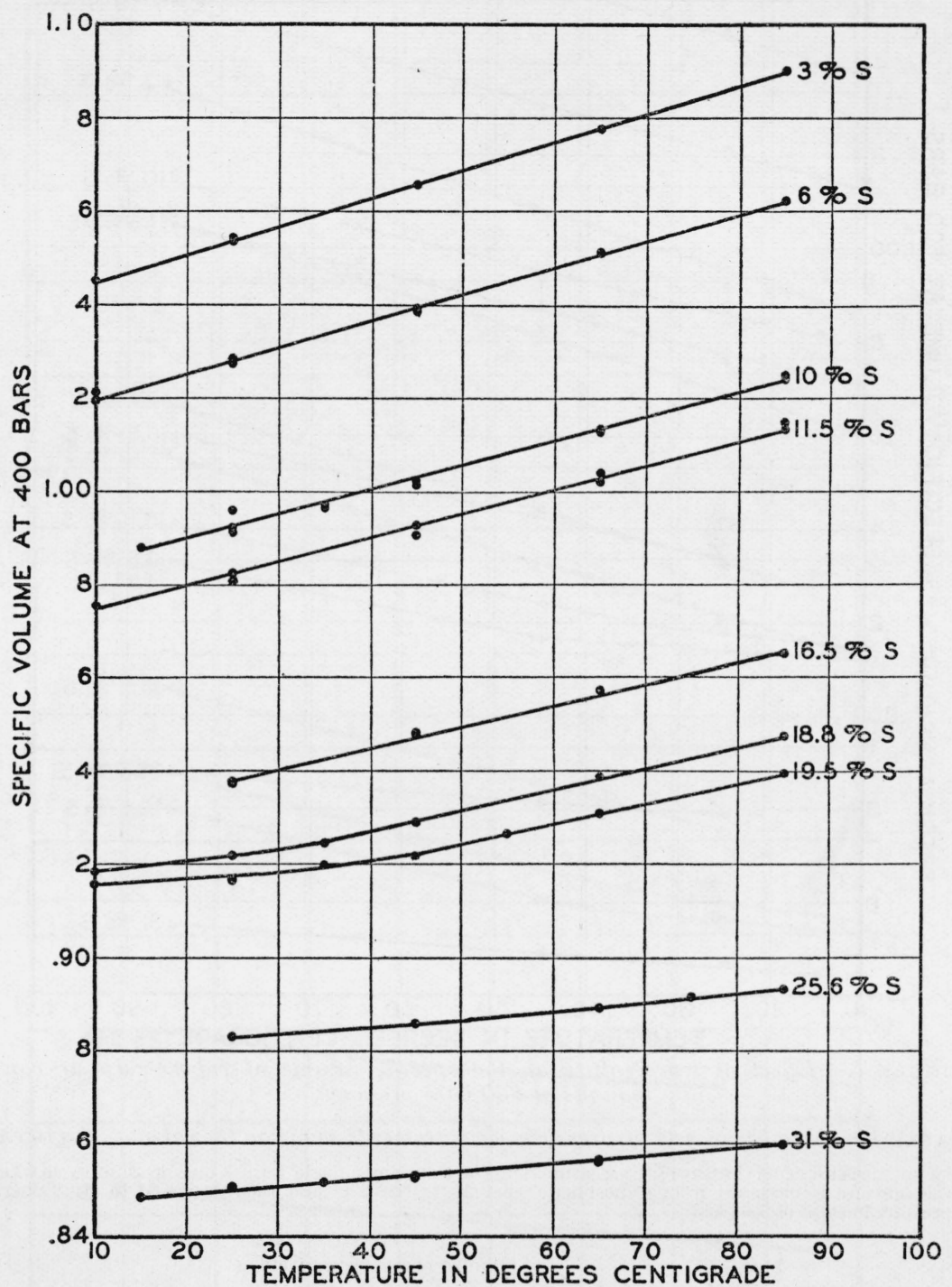

FIGURE 6.-Effect of temperature on the specific volume of rubber-sulphur compounds at 400 bars pressure. 


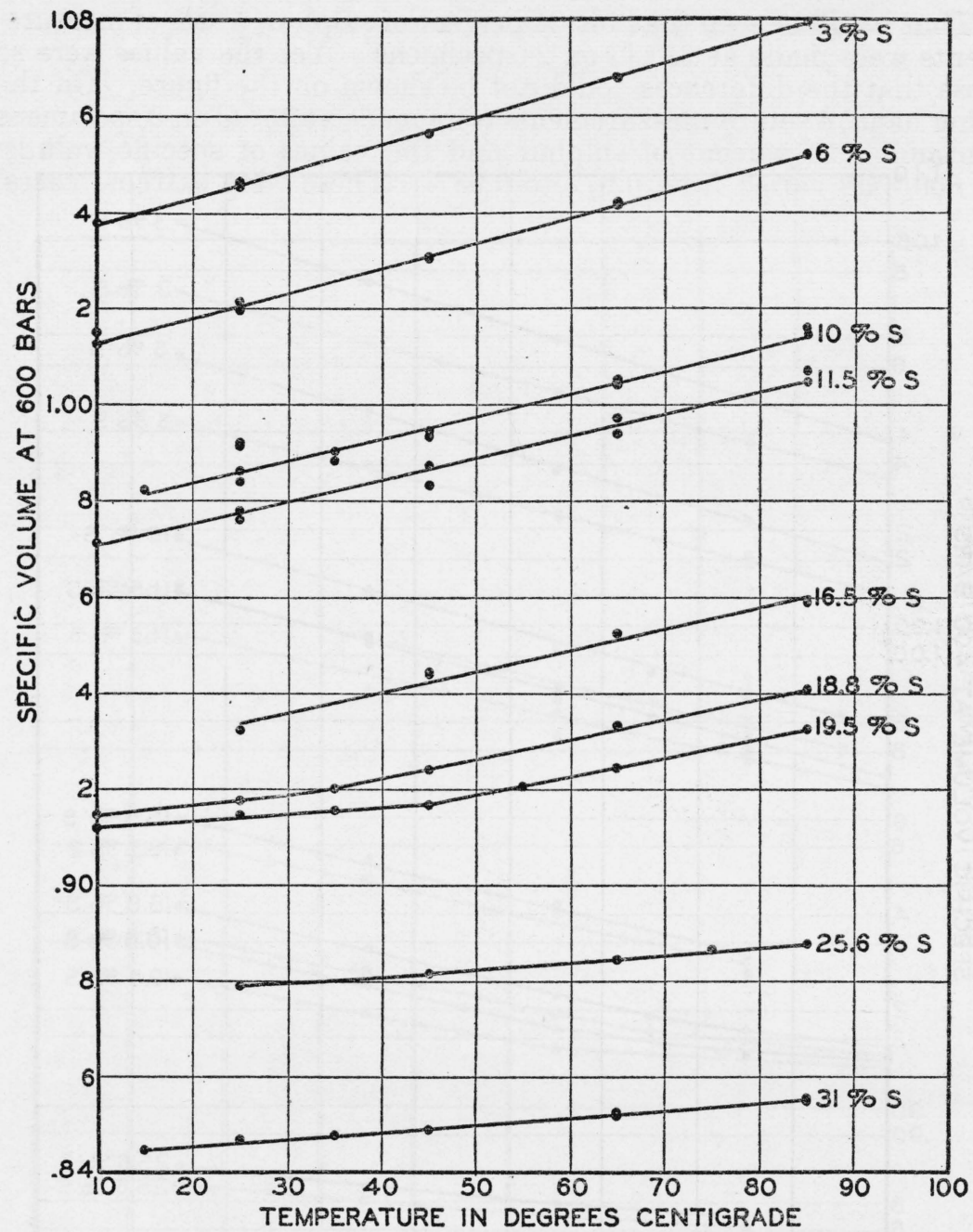

FIgURE 7.-Effect of temperature on the specific volume of rubber-sulphur compounds at 600 bars pressure.

TABLE 1.-Number of sets of pressure measurements made on the various specimens

[A set of measurements consists of the measurements on a specimen made during one pressure cycle when the pressure is increased from atmospheric pressure to 800 bars and then decreased to atmospheric pressure in steps of 200 bars]

\begin{tabular}{|c|c|c|c|c|c|c|c|c|c|c|}
\hline \multirow{2}{*}{$\begin{array}{l}\text { Sulphur } \\
\text { content }\end{array}$} & \multirow{2}{*}{$\begin{array}{l}\text { Num- } \\
\text { ber of } \\
\text { speci- } \\
\text { mens }\end{array}$} & \multicolumn{9}{|c|}{ Number of sets respectively at } \\
\hline & & $10^{\circ} \mathrm{C}$ & $15^{\circ} \mathrm{C}$ & $25^{\circ} \mathrm{C}$ & $35^{\circ} \mathrm{C}$ & $45^{\circ} \mathrm{C}$ & $55^{\circ} \mathrm{C}$ & $65^{\circ} \mathrm{C}$ & $75^{\circ} \mathrm{C}$ & $85^{\circ} \mathrm{C}$ \\
\hline $\begin{array}{l}\text { Percent } \\
3\end{array}$ & 1 & 1 & & 3 & & 1 & & 1 & & 1 \\
\hline 6 & 1 & 2 & & 4 & & 2 & & 2 & 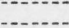 & 1 \\
\hline 10 & 2 & & 1 & 4 & 2 & 2 & & 3 & & 2 \\
\hline 11.5 & 2 & 1 & & 2 & & 2 & $-\ldots$ & 2 & (n) & 2 \\
\hline $\begin{array}{l}16.5 \\
18.8\end{array}$ & $\begin{array}{l}1 \\
1\end{array}$ & 1 & & $\begin{array}{l}3 \\
1\end{array}$ & 1 & $\begin{array}{l}2 \\
1\end{array}$ & & $\begin{array}{l}1 \\
1\end{array}$ & 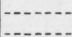 & $\begin{array}{l}1 \\
1\end{array}$ \\
\hline 19. 5 & 1 & 1 & (n) & 2 & 1 & 1 & 1 & 1 & (n) & 1 \\
\hline $\begin{array}{l}25.6 \\
31\end{array}$ & $\begin{array}{l}1 \\
2\end{array}$ & $\cdots$ & 1 & $\begin{array}{l}1 \\
5\end{array}$ & 2 & $\begin{array}{l}1 \\
3\end{array}$ & & $\begin{array}{l}1 \\
4\end{array}$ & 1 & $\begin{array}{l}1 \\
3\end{array}$ \\
\hline
\end{tabular}


Thus it will be seen that for 31 percent of sulphur, 5 sets of measurements were made at $25^{\circ} \mathrm{C}$ on 2 specimens. Yet the values were so close that the differences could not be shown on the figure. On the other hand, 4 sets of measurements were made at $25^{\circ} \mathrm{C}$ on 2 specimens containing 10 percent of sulphur and the values of specific volume at 800 bars varied from 0.977 to 0.987 . These were extreme cases.

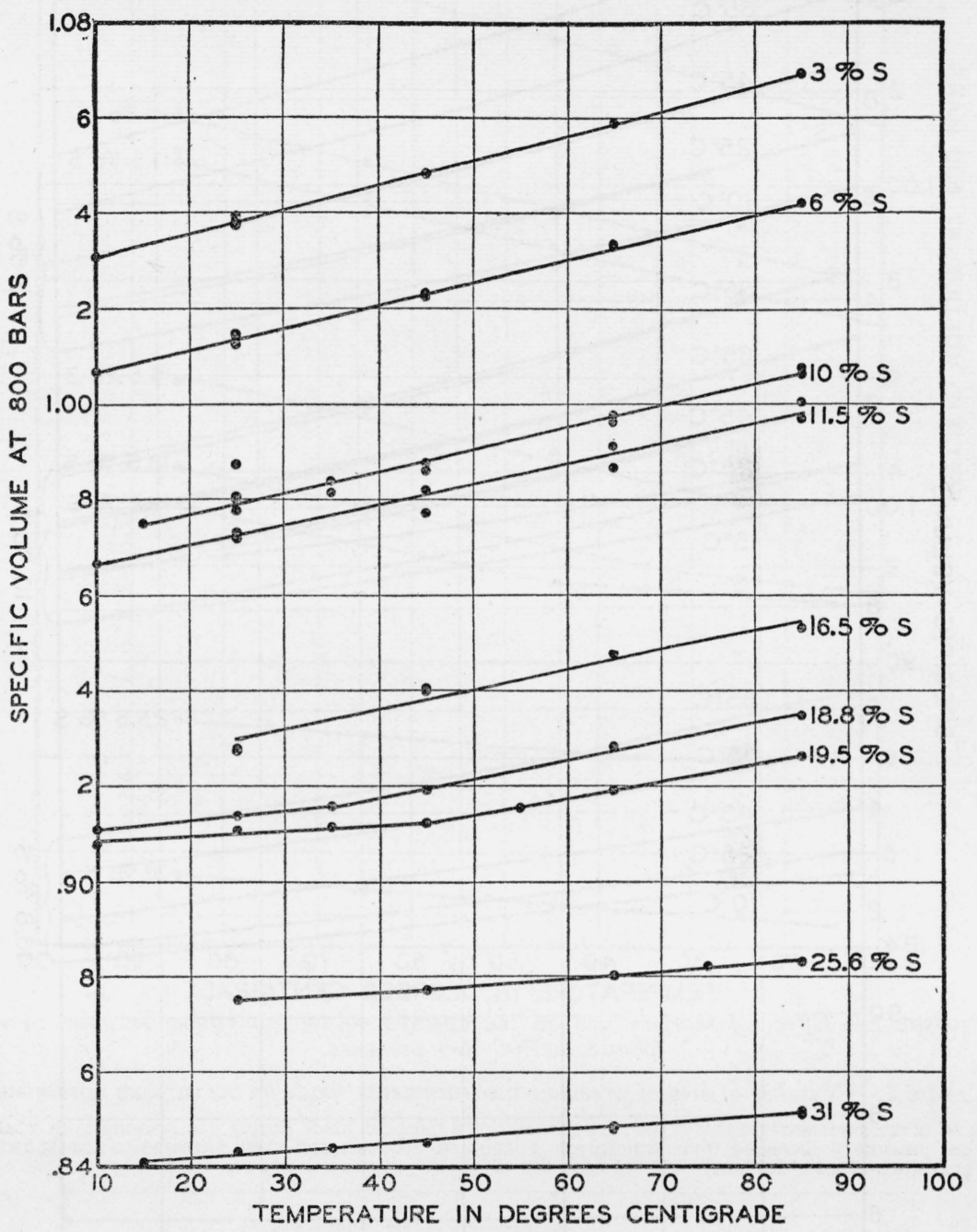

FIGURE 8.-Effect of temperature on the specific volume of rubber-sulphur compounds at 800 bars pressure.

The variability in the results was due to lack of stability and reproducibility of the specimens, since the pressure and length measurements could be made with far greater accuracy than the results indicate. The pressure gage was capable of measuring pressure differences of $1 / 2$ bar and, during calibration, measurements could be reproduced with an error of less than 2 bars. An error of 2 bars would cause a 
maximum error in length of about $0.003 \mathrm{~cm}$ for the specimen of highest compressibility, which is equivalent to an error in specific volume of

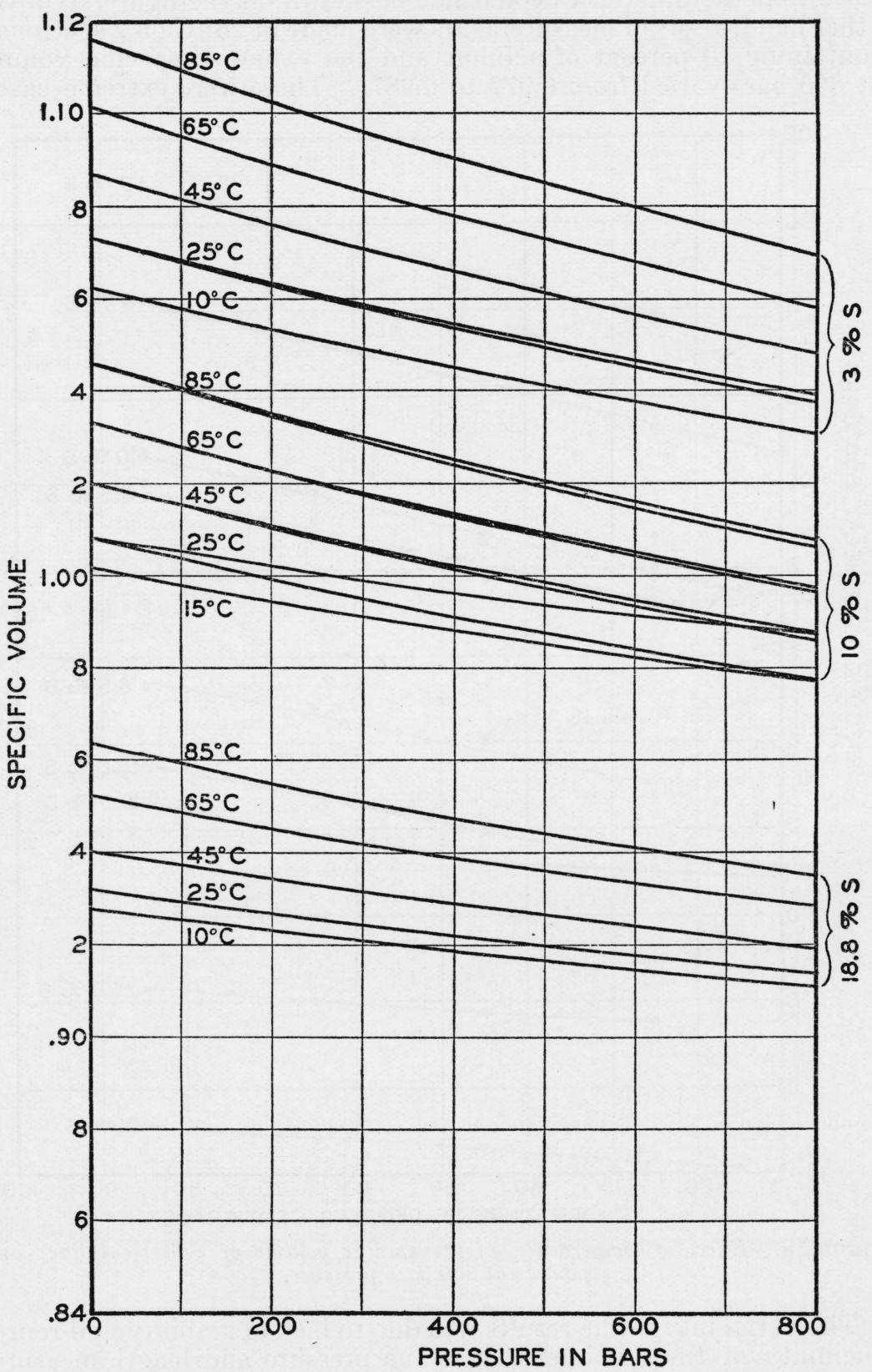

FIGURE 9.-Effect of pressure on the specific volume of rubber-sulphur compounds containing 3,10 , and 18.8 percent of sulphur.

about 1 part in 10,000 . The measurement of change in length was sufficiently?accurate so that a change of $0.0003 \mathrm{~cm}$ could be measured. 
This is equivalent to a change in specific volume of about 1 part in 100,000 . This probably represents the reproducibility of the measurement of change in length since the microscope and specimens were

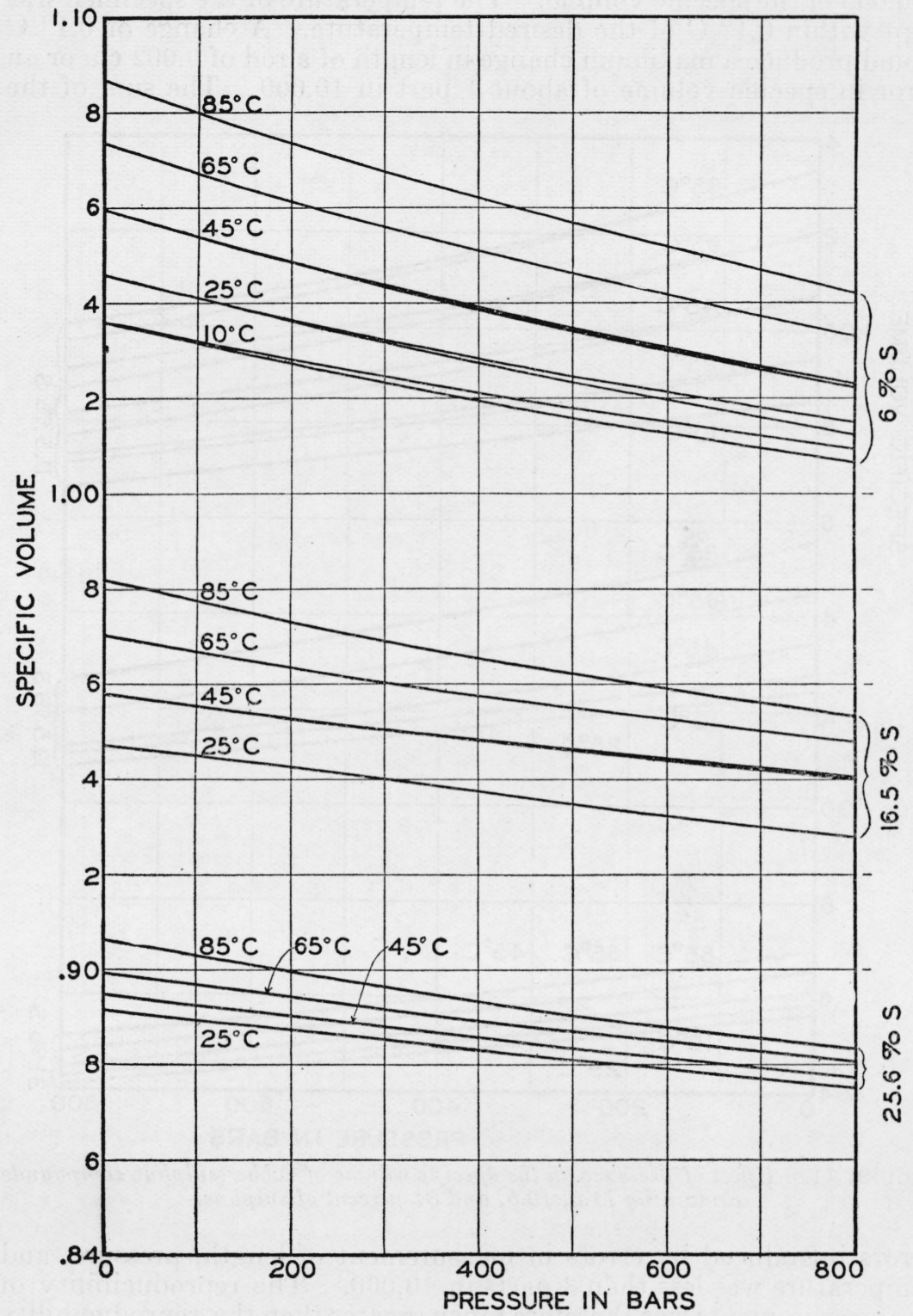

FIGURE 10.-Effect of pressure on the specific volume of rubber-sulphur compounds containing $6,16.5$, and 25.6 percent of sulphur.

supported by separate brackets on a brick wall and the changes in pressure in the chamber could not affect the distance between the brackets. As mentioned above, the total length of the specimen was 
measured to $0.05 \mathrm{~cm}$. Since the total length was used only in the determination of the change in specific volume with pressure, an error of $0.05 \mathrm{~cm}$ in total length introduced an error of less than 3 parts in 100,000 in the specific volume. The temperature of the specimen was kept within $0.1^{\circ} \mathrm{C}$ of the desired temperature. A change of $0.1^{\circ} \mathrm{C}$ would produce a maximum change in length of a rod of $0.002 \mathrm{~cm}$ or an error in specific volume of about 1 part in 10,000 . The sum of the

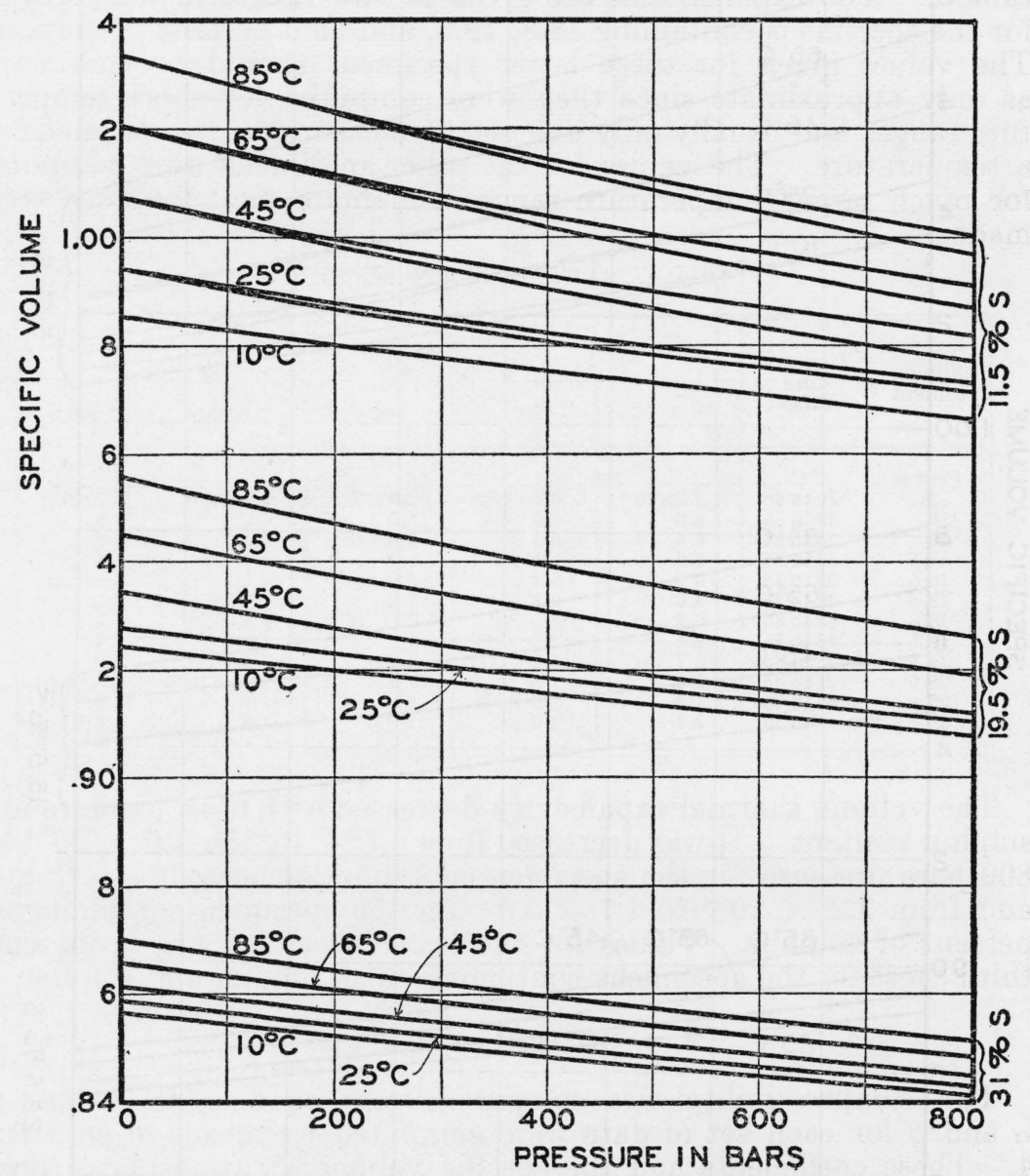

FIGURE 11.-Effect of pressure on the specific volume of rubber-sulphur compounds containing 11.5, 19.5, and 31 percent of sulphur.

errors introduced by errors in measurement of length, pressure, and temperature was less than 3 parts in 10,000. The reproducibility of the measurements was therefore much greater than the reproducibility of the results.

The results on the specimens of high sulphur content were much more reproducible than those on specimens of a low sulphur content. There was some variability in the results on the specimen containing 3 percent of sulphur, but not as much as in the results on the specimens containing from 6 to 16.5 percent of sulphur. Instability in 
the properties of specimens in this range of sulphur content was noticed in previous work.

\section{VOLUME THERMAL EXPANSIVITY}

The volume thermal expansivity as obtained from the slopes of the straight lines drawn through the points in figures 4 to 8 are given in table 2. The expansivities are given in two ranges of temperature for the specimens containing 18.8, 19.5, and 25.6 percent of sulphur. The values given for these latter specimens should be considered as only approximate since they were computed for short temperature ranges and usually only one set of measurements was made at a temperature. The values for the other specimens were computed for much larger temperature ranges and more measurements were made.

TABLE 2.-Volume thermal expansivity

\begin{tabular}{|c|c|c|c|c|c|c|}
\hline \multirow{2}{*}{$\begin{array}{l}\text { Sulphur } \\
\text { content }\end{array}$} & \multirow{2}{*}{$\begin{array}{c}\text { Tempera- } \\
\text { ture } \\
\text { range }\end{array}$} & \multicolumn{5}{|c|}{ Pressure in bars } \\
\hline & & 1 & 200 & 400 & 600 & 800 \\
\hline Percent & ${ }^{\circ} \mathrm{C}$ & & & & & \\
\hline 3 & 10 to 85 & 6. $7 \times 10^{-4}$ & 6. $2 \times 10^{-4}$ & $5.8 \times 10^{-4}$ & $5.4 \times 10^{-4}$ & $5.0 \times 10^{-4}$ \\
\hline 6 & 10 to 85 & 6.6 & & 5. 6 & & \\
\hline 10 & 15 to 85 & 6. 4 & 5.8 & 5.4 & 5.1 & \\
\hline 11.5 & 10 to 85 & 6. 6 & 5.8 & 5.3 & 4.7 & 4.4 \\
\hline 16.5 & 25 to 85 & 6.2 & 5.4 & 5. 0 & 4.5 & 4.4 \\
\hline 18.8 & 10 to 25 & 3. 0 & 2.6 & 2.4 & 2.1 & \\
\hline 18.8 & 45 to 85 & 6.2 & 5.5 & 5.0 & 4.6 & 4.2 \\
\hline 19.5 & 10 to 25 & 2.5 & 2. 2 & 1.8 & 1.6 & 1.4 \\
\hline 19.5 & 45 to 85 & 5. 7 & 5.2 & 4.8 & 4.3 & 3.9 \\
\hline 25.6 & 25 to 45 & 1. 9 & 1.6 & 1.5 & 1.4 & 1.3 \\
\hline 25.6 & 65 to 85 & 4. 0 & 3.0 & 2.4 & 1.9 & 1.6 \\
\hline 31 & 15 to 65 & 2. 1 & 2.0 & 1.9 & 1.8 & 1.7 \\
\hline
\end{tabular}

The volume thermal expansivity decreased with both pressure and sulphur content. It was decreased from $6.7 \times 10^{-4}$ to $5.0 \times 10^{-4}$ by 800 bars pressure for the specimen containing 3 percent of sulphur, and from $2.2 \times 10^{-4}$ to $1.7 \times 10^{-4}$ for the specimen containing 31 percent of sulphur. Values for the latter specimen are about onethird those for the specimens containing small amounts of sulphur.

\section{COMPRESSIBILITY}

The compressibility was computed from eq 6 . The values of $\alpha$ and $\beta$ for each set of data were computed by means of eq 3 and 4. These coefficients and the specific volume at atmospheric pressure, $V_{a}$, were found to be functions of both the temperature and sulphur content of the specimen. From figure 4 it is seen that $V_{a}$ increases linearly with the temperature for all specimens containing up to 16.5 percent of sulphur. When $V_{a}$ at $25^{\circ} \mathrm{C}$ is plotted against the percentage of combined sulphur it is found that it decreases linearly with the percentage of sulphur up to 16.5 percent and from 18.8 to 31 percent. The coefficients $\alpha$ and $\beta$ increase with the temperature and decrease with the sulphur content. The relationship appears to be linear in each case although there is a wide spread of values in some cases. Assuming linear relationships, it was possible to set up two sets of empirical equations for the values of $V_{a}, \alpha$, and $\beta$, one for each side of the boundary marking the change in slope of the 
curves. For temperatures between 10 and $85^{\circ} \mathrm{C}$ and for specimens containing up to $X$ percent of sulphur, where $X$ is given by the equation $X=(T+30) / 3.7$ and $T$ is the temperature in degrees centigrade, the following equations hold:

$$
\begin{aligned}
V_{a} & =1.1015+0.00073(T-25)-X[0.00932+0.000007(T-25)] \\
\alpha & =-10^{-6}\{53.7+0.258(T-25)-X[1.35-0.00217(T-25)]\} \\
\beta & =10^{-9}[12.0+0.083(T-25)-0.34 X]
\end{aligned}
$$

For temperatures between 10 and $85^{\circ} \mathrm{C}$ and for specimens containing between $X$ and 32 percent of sulphur, where $X$ is given by the equation $X=(T+42) / 3.7$, the following equations hold:

$$
\begin{aligned}
V_{a} & =1.0450+0.00038(T-25)-X[0.00601+0.0000064(T-25)] \\
\alpha & =-10^{-6}\{35.6+0.326(T-25)-X[0.352+0.00672(T-25)]\} \\
\beta & =10^{-9}[9.1+0.0683(T-25)-0.221 X]
\end{aligned}
$$

When these values of $V_{a}, \alpha$, and $\beta$ were substituted in eq 2 , equations were obtained which gave the specific volume with an accuracy comparable to the accuracy of the data within the limits specified, with a few exceptions. The computed values of the specific volume agree to about 1 part in 1,000 with experimental values for the specimens containing 3,6 , and 31 percent of sulphur and with part of the experimental values for the specimens containing $10,11.5,16.5$, $18.8,19.5$, and 25.6 percent of sulphur. In one case only the computed value differs from a measured value by more than 4 parts in 1,000 . The computed value for the specimen containing 25.6 percent of sulphur at $85^{\circ} \mathrm{C}$ is lower than the measured value by about 12 parts in 1,000 .

The values for the compressibility may be readily determined within the limits specified from eq 6 by substituting in it the correct values of $\alpha$ and $\beta$ as computed from eq 8 and 9 or 11 and 12. The values for the specimens containing 3 and 31 percent of sulphur are shown in figure 12. These were the extreme values of the compressibility which were obtained.

\section{DISCUSSION}

The method used for the determinations of the specific volumes and compressibilities of rubber was such that the precision of measurement was much higher than the reproducibility of results. As mentioned above the measurements could be made to less than 3 parts in 10,000 . The reproducibility of the results was such that during any set of measurements through a pressure cycle at a fixed temperature the values obtained for increasing pressures agreed with those for decreasing pressures to about 2 parts in 10,000 . However, if a duplicate specimen were made or if the specimen were taken through a cycle of temperatures and measured again at the original temperature, the measurements in many cases did not agree closer than about 2 or 3 parts in 1,000 at 800 bars. In one case the measurements on different specimens did not agree closer than 1 part in 100 . The values of specific volume are therefore probably accurate to 0.2 or 0.3 percent in most cases and in any case to 1 percent.

There is very little published information on the compressibility of rubber with which to compare the present work. Adams and Gibson 
have measured 3 samples of rubber at pressures above 1,000 bars. $^{13}$ Only one of these had a composition falling in the group used in the present investigation. The extension of the curve of Adams and Gibson for a specimen containing 10 percent of sulphur gives a compressibility of about $29.4 \times 10^{-6}$ at 800 bars. The compressibility for the same composition obtained from eq 6, using the values of $\alpha$ and $\beta$ computed from eq 8 and 9 , is $26.4 \times 10^{-6}$ at $25^{\circ} \mathrm{C}$. The values

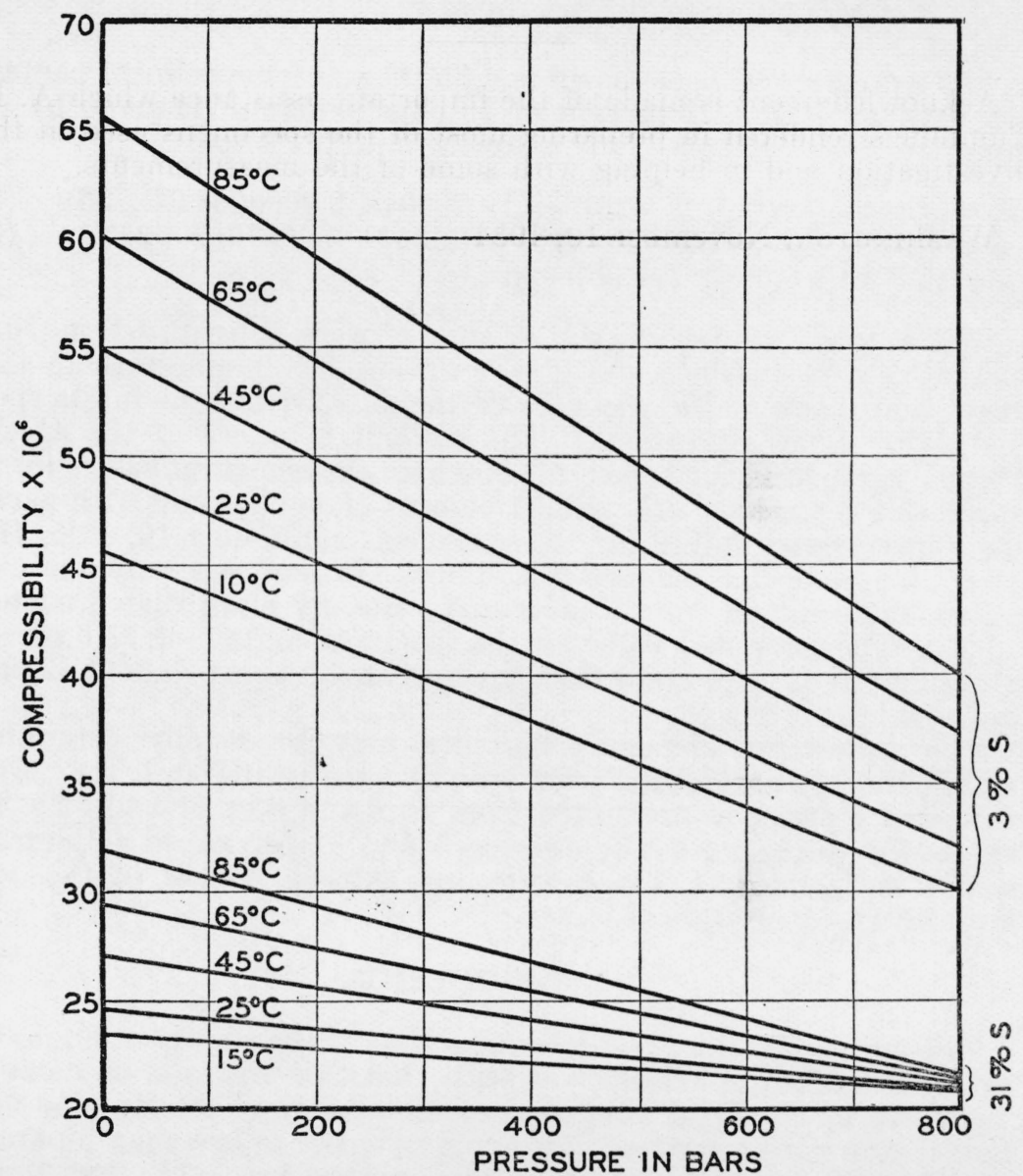

FIGURE 12.-Effect of pressure on the compressibility of rubber-sulphur compounds containing 3 and 31 percent of sulphur.

obtained for the individual sets of data, where $\alpha$ and $\beta$ were computed from eq 3 and 4 , varied from 15.5 to $29.4 \times 10^{-6}$. The value given by Adams and Gibson is then about the same as the highest value obtained by the author. But the change of the compressibility with pressure obtained by the author is very much greater than that given by the curve of Adams and Gibson.

The specific volumes of rubber-sulphur compounds at atmospheric pressure have been determined by Kimura and Namikawa. ${ }^{14}$ They

13 J. Wash. Acad. Sci. 20, 213 (1930).

11 J. Soc. Chem. Ind., Japan, 32 (supplemental binding) 196B (1929). 
used specimens made from crude rubber. The values which they reported are in agreement with those given here for specimens containing up to 16.5 percent of sulphur. For specimens containing larger amounts of sulphur the values of specific volume given by them are lower than those given here. The "knees" which they describe were observed by the author, but they were generally found to come at lower temperatures than those reported by Kimura and Namikawa.

Acknowledgment is made of the important assistance which A. D. Cummings rendered in preparing most of the specimens used in this investigation and in helping with some of the measurements.

Washington, November 10, 1934. 